\title{
Dietl's crisis: an under appreciated clinical entity in the paediatric population
}

\author{
Varunkumar Maddileti 이, ${ }^{1}$ Suhasini Gazula, ${ }^{1}$ Praveena Dantala, ${ }^{1}$ Maddur Srinivas ${ }^{2}$
}

${ }^{1}$ Paediatric Surgery, ESIC Medical College and Hospital Hyderabad, Hyderabad, Telangana, India

${ }^{2}$ Paediatric Surgery, All India Institute of Medical Sciences, New Delhi, India

\section{Correspondence to} Dr Suhasini Gazula; drgazulaesic@gmail.com

Accepted 12 July 2021
Check for updates

(c) BMJ Publishing Group Limited 2021. No commercial re-use. See rights and permissions. Published by BMJ.

\footnotetext{
To cite: Maddileti $V_{\text {, }}$ Gazula S, Dantala P, et al. BMJ Case Rep 2021;14:e244943. doi:10.1136/bcr-2021244943
}

\section{DESCRIPTION}

Dietl's crisis is described as episodic, crampy upper abdominal pain, nausea and vomiting associated with intermittent renal pelvi-ureteric junction (PUJ) obstruction. A child with this crisis often has a delay in diagnosis, with the clinical entity being underdiagnosed. Dietl's crisis is one of the curable causes of intermittent abdominal pain. ${ }^{1}$ Pain is due to intermittent renal pelvis dilation secondary to delayed ureteric drainage, often during periods of increased fluid intake. Ureteric hold up may be associated with an aberrant crossing vessel, high insertion of the ureter into the pelvis or congenital narrowing. ${ }^{1}$ We report two cases of Dietl's crisis, a 2-month-old baby and a 6-year-old child, they were picked up by clinical examination and ultrasonography.

A 2-month-old male child with known bilateral antenatal hydronephrosis presented with pain and right abdominal fullness (figure 1A). Ultrasonography showed bilateral hydronephrosis (figure 1B), which reduced over 3 days (figure 1C) without intervention. Dynamic scintigraphy demonstrated bilateral PUJ obstruction with left and right-sided function at $42 \%$ and $58 \%$, respectively (figure 1D). Voiding cystourethrogram was performed to exclude vesicoureteral reflux and posterior urethral valve. The infant initially had an open right Anderson Hynes (AH) pyeloplasty, which demonstrated a hugely dilated pelvis (figure 1E) and a left pyeloplasty 6 weeks later. There were no crossing vessels.

Similarly, a 6-year-old girl presented with a history of intermittent pain and left abdominal fullness for 2 years, and the antenatal scans were not available. Ultrasonography during Dietl's crisis demonstrated gross left hydronephrosis, with an anteroposterior diameter (AP) of pelvis $4.2 \mathrm{~cm}$ (figure 2A) and postcrisis ultrasound demonstrated reduced hydronephrosis, AP pelvis $1.2 \mathrm{~cm}$ (figure 2C). Dynamic scintigraphy showed left PUJ obstruction (figure 2B). The child underwent an open left $\mathrm{AH}$ pyeloplasty. There was no crossing vessel. The child made an uneventful recovery with the resolution of symptoms.

Dietl's crisis is first reported by Josef Dietl in 1864. The incidence of Dietl's crisis has been reported to be from $11 \%$ to $15 \%$ in children. ${ }^{2}$ Ten case reports and one case series were published in the last 10 years. Among them, three reports had crossing vessels across PUJ. A study by Chen $\mathrm{Z}$ et al has 119 cases of intrinsic PUJ obstruction, 21 cases of ureteric polyps, 7

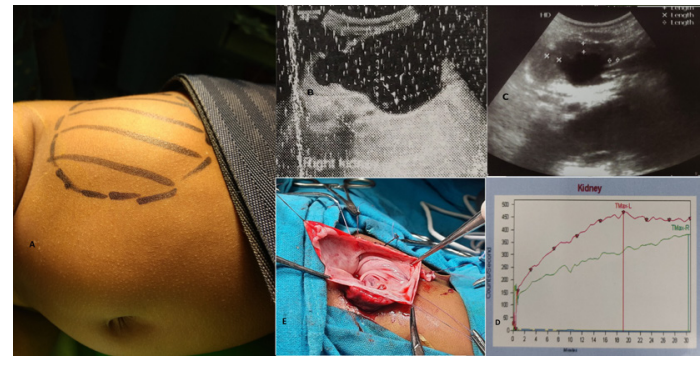

Figure 1 (A) Right abdominal mass, (B) ultrasound showing right hydronephrosis, anteroposterior pelvis $4 \mathrm{~cm}$, at Dietl's crisis, (C) post crisis ultrasound demonstrating reduced hydronephrosis, (D) dynamic scintigraphy showing bilateral pelvi-ureteric junction obstruction; (red—right, green-left), (E) open pyeloplasty demonstrating grossly dilated renal pelvis.

cases of crossing vessel across PUJ and 3 cases of high insertion of the ureter to the pelvis as cause for Dietl's crisis. The incidence of crossing lower polar vessels is $11 \%$ to $20 \%$ of PUJ obstruction cases. ${ }^{3}$ The absence of associated urologic symptoms contributes to the late referral to a paediatric urologist. ${ }^{4}$ Fluid loading or feeding in young children causes Dietl's crisis and children often become symptomatic during the forced diuresis phase of dynamic scintigraphy scan with a diuretic. Once the proper diagnosis is made, patients are well served by a pyeloplasty with the resolution of pain symptoms. Alternative procedures and approaches include minimally invasive keyhole surgery, ureteric hitch, endoscopic balloon dilation or stenting. Postcrisis functional improvement has been reported in the literature, indicating the need for surgical intervention and

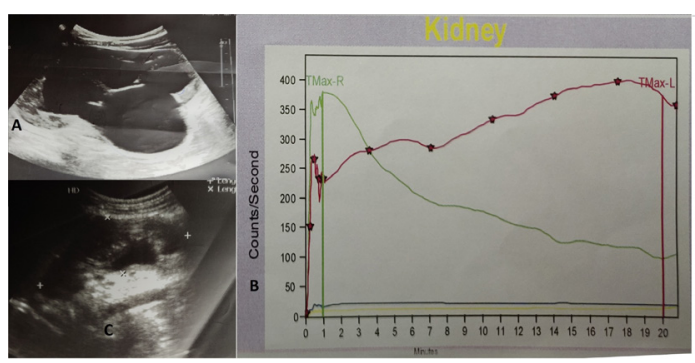

Figure 2 (A) Ultrasound showing left hydronephrosis, anteroposterior pelvis $4.2 \mathrm{~cm}$, at Dietl's crisis, (B) dynamic scintigraphy showing left pelvi-ureteric junction obstruction (red) and normal right drainage (green). (C) Post crisis ultrasound demonstrating reduced hydronephrosis (The authors created all the figures in the article; none of them reused from other sources). 
that relief in obstruction would result in good postoperative functional recovery. ${ }^{5}$

\section{Patient's perspective}

Patient 1 : I do not know how we could possibly thank doctors for treating our baby. We were tensed when we got to know that our baby has swollen kidneys at pregnancy itself. Doctors reassured us that after delivery, baby can be treated. Our baby was born and was having abdomen fullness on right side, which used to increase and decrease in size. Doctors did tests and told us that there is block in the kidney drainage and requires surgery on both sides one side at a time. Our baby recovered well postsurgery and there is no swelling of abdomen now. Surgery to other kidney is awaited. Doctors told that kidney scan will be done after 1 year postsurgery to know the function of kidney and drainage. By God's grace, everything went well, we wish the best for further treatment and recovery of the baby.

Patient 2: we would like to thank doctors for successfully treating our child. Since many years, our child was having pain symptoms and increase and decrease of swelling in the abdomen. Ours is a small village, local doctors thought that the symptoms were due to some gastric problem and was given medicines. But symptoms used to occur again and again. We were referred to this hospital. Doctors noted my complaints and did tests and told us that there is block in the left kidney and surgery should be done. Surgery was done and our child recovered well. Doctors told us that kidney function scan will be done after 1 year postsurgery to know the function and drainage of the kidney. We are praying for our child and thank doctors for identifying the problem and treated our child. We are following up regularly with our doctors and till now our child is fine.

\section{Learning points}

- Children without evidence of antenatal hydronephrosis often have a delayed diagnosis of Dietl's crisis as a cause of intermittent abdominal pain.

- Abdominal ultrasound scanning should be performed at the time of the crisis to fully appreciate renal pelvis dilation.

- Dietl's crisis is curable with surgical intervention.

Contributors VM-planning, conduct, reporting, conception and design. SGplanning, conduct, reporting, conception and design. PD-acquisition of data. MS - analysis and interpretation of data. The pictures were collected by VM and PD. All authors contributed to the drafting of the manuscript. MS and SG helped in the final editing of the revised manuscript. All authors approved the submission of the revised version.

Funding The authors have not declared a specific grant for this research from any funding agency in the public, commercial or not-for-profit sectors.

Competing interests None declared.

Patient consent for publication Parental/guardian consent obtained.

Provenance and peer review Not commissioned; externally peer reviewed.

\section{ORCID iD}

Varunkumar Maddileti http://orcid.org/0000-0002-7523-013X

\section{REFERENCES}

1 Flotte TR. Dietl syndrome: intermittent ureteropelvic junction obstruction as a cause of episodic abdominal pain. Pediatrics 1988:82:792-4.

2 Fu K, Jia W, Fu W, et al. Abdominal pain as a result of intermittent hydronephrosis. Eur Rev Med Pharmacol Sci 2018;22:3126-9.

3 Chen Z, Lin $\mathrm{H}, \mathrm{Xu} \mathrm{M}$, et al. The clinical manifestations of intermittent hydronephrosis and their relationship with renal function in pediatric patients. J Pediatr Urol 2020;16:458.e1-458.e6.

4 Alagiri M, Polepalle SK. Dietl's crisis: an under-recognized clinical entity in the pediatric population. Int Braz J Urol 2006;32:451-3.

5 Parida GK, Tripathi M, Kumar K, et al. Objective improvement in renal function post-Dietl's crisis: documented on renal dynamic scintigraphy. Indian J Nucl Med 2016:31:240-1.

Copyright 2021 BMJ Publishing Group. All rights reserved. For permission to reuse any of this content visit

https://www.bmi.com/company/products-services/rights-and-licensing/permissions/

BMJ Case Report Fellows may re-use this article for personal use and teaching without any further permission.

Become a Fellow of BMJ Case Reports today and you can:

- Submit as many cases as you like

Enjoy fast sympathetic peer review and rapid publication of accepted articles

- Access all the published articles

Re-use any of the published material for personal use and teaching without further permission

Customer Service

If you have any further queries about your subscription, please contact our customer services team on +44 (0) 2071111105 or via email at support@bmj.com.

Visit casereports.bmj.com for more articles like this and to become a Fellow 